\section{Italian university structure}

SIR - Many readers not familiar with the structure of Italian universities may be confused by the recent controversy aired in these columns ${ }^{1-5}$. As a foreigner (Australian) with several years experience of Italian academic life, I am perhaps well placed to try to explain some of the more unusual aspects of academic promotion that engender so much excitement and rancour in Italy.

Italians are renowned for their creativeness and adaptability, but their institutions are not, and the university system is sadly no exception. Despite some recent moves towards limited autonomy, all Italian universities remain firmly under the centralized control of the Ministry of Universities and Research. Individual universities can neither appoint nor promote their own professors. To promote a colleague, a department must apply to the ministry for a new position at the higher level, after lengthy and often heated debate by the full councils of the department, school of studies and faculty. If the request is granted, the chair is listed to be filled in the next concorso, the centralized selection procedure, with a total lead time of around five years. Vacancies from all universities are gazetted together in groups of similar disciplines (with no advertisements in Nature or the like). Applicants apply for whole groups of positions, not for individual chairs, expressing no preference for faculty, university city or region. This explains in part why many Italian academics, like the not atypical characters of David Lodge's Small World ${ }^{6}$, teach in cities remote from their abode: I myself live in Pisa.

For each group of positions, a commission of professors is elected by all professors in the relevant discipline. Of those elected for each commission, 60 per cent are eliminated at random, in a rare example of a selection procedure where randomness is considered to improve performance (by noise linearization?). Those remaining have the task of selecting the best applicants, considering only the scientific and didactic merits of the candidates. Full professors are selected on the basis of a written curriculum (without interview), while associate selection is a more gruelling affair, including a public lecture on an unfamiliar topic at 24 hours notice. Only after selection do applicants apply to the faculties of their preferred univesities, who in turn select their preferred candidates (but in practice there is often no real choice ${ }^{5}$ ).

Now, does any reader believe that the system really works like this? Do the members of the departments and facul- ties of the individual universities have so little say in the selection of their professors? Do candidates apply for pools of vacancies, with no preference for research institutions or prior knowledge of where they may end up? Of course not. Unless the preferred candidates completely disgrace themselves in the oral examination, the concorso is usually only a legal formality. Most of the real selection occurs behind the scenes, in huddled discussions at conferences and other clandestine encounters.

It is not hard to imagine how the discrepancy between the theoretical and actual selection criteria leaves the system wide open to criticism by disgruntled losers. Applicants who are best on paper may not be selected for a host of valid reasons, including local research, teaching and clinical requirements. However, if the real reasons are not legally acceptable, others must be invented, and this ambiguity can clearly lead to resentment. But the real problem arises from the fact that once one accepts that the law has to be bent to allow the system to work, it is a small step to bend it a bit further to make the system work for less honourable motives. As Alan Friedman ${ }^{7}$ convincingly argues for the business sector, academic institutions in Italy remain largely feudal. Many senior professors (still often referred to as "barons") view university chairs as fiefs to be awarded to loyal vassals (ensuring their eternal fealty) rather than to independently creative scientists. Competition for control of the fiefs is keen, with deals, vote-trading and other forms of favour-swapping, including grant distribution (for which there is no peer review). Alliances form along similar lines to those in the thirteenth century city states, and conspiracies and conspiracy theories abound.

I am in no position to express an opinion of the cases published in Nature $^{1-5}$, but there is no shortage of concorso anecdotes in Italy. For example, a close friend recently applied for promotion to associate-professorship. In the unofficial 'pre-concorso' hearings, her curriculum (including four firstauthor papers in Nature) led her to be judged a clear leader, and she so impressed the commission at her interview and public lecture that a commission member said that "she performed so well it will be extremely difficult for us to find a way to eliminate her". But they did, and all positions went to feal vassals of the commissioners and their allies. My friend was eliminated through no fault of her own, but because the commission considered that her padrone (who supervised her $\mathrm{PhD} 12$ years ago but has not since worked with her) had not participated fully in the concorso games.

It is difficult to assess quantitatively the degree to which promotion is more unfair in Italy than elsewhere. Certainly, we all believe that our own promotions are merited and, despite the unusual selection techniques, I suspect that the great majority are. However, the few blatantly outrageous promotions, combined with the ambiguity and hypocrisy inherent in the system, have created a general perception of corruption and nepotism, and this perception is seriously eroding morale. And the fact that sycophancy is more highly prized than originality is a real impediment to innovative research. Concorso powermongering is a sport for the barons, with little consideration of its impact on the young (and often not-so-young) applicants who must survive the trial-by-fire oral examination, only to learn that the real selection was made months earlier on the basis of entirely different criteria. Why not dispense with the charade?

Most Italians agree that the system has major problems, and many talk of little else, but few agree on the remedy. Certainly it is unlikely that change will come from within. Not many professors seek the honour of serving on selection commissions (involving up to 20 days out of town, and maybe 150 hours of boring committee work) unless they have good reason to do so. But little is to be gained by vilifying the individual commissioners, most of whom are honest scientists trying to make an unworkable system work. My personal view is that the only way to restore some dignity to Italian academic promotion is to accept that centralized control is unrealistic, and to give some real autonomy to the universities, allowing them to select and promote staff to suit their local needs. Many cynics will argue that freedom from centralized control will lead only to increased nepotism, but I believe that this unfortunately widespread aspersion on the integrity of Italian scientists is unwarranted. The system is at fault, not the individuals. With appropriate mechanisms, such as linking university funding to performance, universities would soon see the advantages of choosing good people, and might even consider advertising for them.

\section{David Burr}

(Professore ordinario di Psicologia),

Università di Roma,

Via dei Marsi, 78, Rome, Italy

1. Gaetani G. F. \& Ferraris, A. M. Nature 353, 10 (1991).

2. Amadori, S. et al. Nature 355, 58, (1992).

3. Baccarani, M. et al. Nature 356, 188 (1992)

4. Auiti, F., Baroni, C. Cao, A. \& Fantoni, A. Nature 356, 188 (1992)

5. Visconti, G. Nature 356, 188-189 (1992).

6. Lodge., D. Small World (Secker and Warburg, London, 1984).

Freidman, A. Agnelli and the Network of Italian Power (Mandarin, London, 1989). 